\title{
NOVAS TECNOLOGIAS E LIBERDADE DE EXPRESSÃO NA PESQUISA CIENTÍFICA: UMA ANÁLISE SOBRE A PROTEÇÃO DE DADOS GENÉTICOS E DE SAÚDE
}

\author{
Fernando Augusto Melo Colussi ${ }^{1}$ \\ Tomlyta Luz Velasquez dos Santos ${ }^{2}$
}

\begin{abstract}
RESUMO: O presente artigo $^{3}$ propõe analisar a proteção dos dados pessoais genéticos e de saúde e seus contrapontos com a liberdade de pesquisa no âmbito da sociedade da informação. Para tanto, abordam-se as informações genéticas na sua perspectiva de dados sensíveis, bem como o uso destas na área médica junto à aplicação de novas tecnologias. Posteriormente, dispõe sobre a liberdade de expressão na atividade científica, tecendo o panorama dos conflitos entre direitos fundamentais. Por fim, avalia o cenário normativo de proteção de dados genéticos, fazendo um paralelo entre o contexto brasileiro e europeu na tutela dos dados pessoais.
\end{abstract}

Palavras-chave: Sociedade da Informação. Informações em Saúde. Dados Genéticos. Direitos da Personalidade. Proteção de Dados Pessoais.

\section{NEW TECHNOLOGIES AND FREEDOM OF SPEECH IN SCIENTIFIC RESEARCH: AN ANALYSIS ON THE PROTECTION OF GENETIC AND HEALTH DATA}

\begin{abstract}
This article aims to analyze the protection of personal genetic and health data, and its counterpoints with the freedom of research within the information society. Therefore, genetic information is approached in the perspective of sensitive data, as well as the use of those in the medical area with the application of new technologies. Subsequently, it provides for freedom of speech in scientific activity, weaving the panorama of conflicts between fundamental rights. Finally, it evaluates the normative scenario of protection of genetic data, making a parallel between the Brazilian and European context in the protection of personal data.
\end{abstract}

Keywords: Information Society. Health information. Genetic data. Rights of the personality. Protection of personal data.

\footnotetext{
${ }^{1}$ Pós-graduado em Direito do Trabalho e Direito Processual do Trabalho pela Fundação Ministério Público (FMP). Mestrando em Direito pela Pontifícia Universidade Católica do Rio Grande do Sul (PUCRS). Advogado. Domiciliado na Rua General Lima e Silva, 757/503, Cidade Baixa, Porto Alegre - RS. E-mail: fernando.colussi@hotmail.com.

${ }^{2}$ Pós-graduada em Biodireito e Mestranda em Direito pela Pontifícia Universidade Católica do Rio Grande do Sul (PUCRS). Bolsista vinculada à CAPES. Advogada. Domiciliada na Av. Caçapava, $\mathrm{n}^{\circ}$ 352, Petrópolis, Porto Alegre - RS. E-mail: tomlyta.velasquez@ hotmail.com.

${ }^{3} \mathrm{O}$ presente trabalho foi realizado com apoio da Coordenação de Aperfeiçoamento de Pessoal Nível Superior - Brasil (CAPES) - Código de Financiamento 001.
}

Rev. de Biodireito e Direito dos Animais | e-ISSN: 2525-9695 | Porto Alegre | v. 4 | n. 2 | p. 1 - 21 | Jul/Dez. 2018 


\section{INTRODUÇÃO}

O estudo da relação entre a liberdade de expressão e a proteção dos dados genéticos e da saúde é tema de grande relevância, e com os constantes avanços da tecnologia na área, se destaca a reflexão acerca da ponderação entre direitos fundamentais de modo a possibilitar a coexistência entre liberdade da pesquisa e a proteção de dados pessoais.

Este artigo busca enfrentar cientificamente o problema da fragilidade do tratamento das informações em saúde, precipuamente os dados genéticos, na realidade digital atual. Nesse aspecto, mister ponderar da relevância do estudo da liberdade de pesquisa genética como direito fundamental não absoluto, aliada à necessidade de um marco regulatório que seja apto a, efetivamente, proteger os dados pessoais.

Assim, pretende-se analisar os dados genéticos, conceituando-os como dados sensíveis, da mesma forma em que os contrapõe com a liberdade de pesquisa, bem como apresentar as informações em saúde sob a perspectiva da sociedade da informação.

Em seguida, será delineado da classificação da pesquisa genética como um direito fundamental de liberdade limitado pela dignidade da pessoa humana para que, então, se possa refletir, com base no exemplo europeu, sobre o contexto regulatório brasileiro no que tange a proteção de dados pessoais.

Como estudo científico que é, empregou-se o método de abordagem dedutivo e os métodos de procedimento histórico, comparativo e funcionalista. $\mathrm{O}$ tipo de pesquisa utilizado foi essencialmente bibliográfica-documental, com análise dos materiais de forma teórica e qualitativa, tendo objetivo exploratório e prescritivo dita soluções para os problemas estudados pela técnica investigativa bibliográfica e documental.

O tema é deveras interessante, sob o ponto de vista acadêmico-operativo, por isto a dedicação desta pesquisa à sua problematização em refletir sobre a relação dialética entre os benefícios e prejuízos causados pelo avanço biotecnológico, de modo a analisar a possibilidade da coexistência entre a efetiva proteção de dados genéticos e da saúde e a promoção e incentivo das pesquisas científicas genéticas. 


\section{INFORMAÇÃO GENÉTICA COMO DADOS SENSÍVEIS}

O avanço da tecnologia na saúde viabilizou uma maior amplitude dos estudos sobre o genoma humano e demais pesquisas envolvendo o mapeamento genético. Tais estudos envolvem diretamente a realização de exames e testes genéticos num número de indivíduos, com vistas a investigação dos genes e a eventual relação com doenças ou demais características de ordem genética.

Os testes genéticos realizados viabilizam o diagnóstico de enfermidades genéticas (ainda que os portadores não sejam afetados por um possível reconhecimento de alguma patologia ou síndrome, eventuais descendentes o poderão ser), detectar doenças graves com maior precocidade possível, e até averiguar a possibilidade do desenvolvimento de alguma mazela, conjugando o estilo de vida do indivíduo à sua predisposição genética. Também, tais testes podem ser empregados para viabilizar um maior conhecimento de determinada população e, então, implementar políticas públicas. Ademais, podem servir como meio de prova (para fins de testes de paternidade, ou ainda na seara criminal, para citar alguns exemplos). Além disso, também viabiliza um estudo comportamental do sujeito, no que diz respeito à sua inteligência ou características psicológicas (ECHTERHOFF, 2010).

Denota-se que a informação genética não apenas identifica o sujeito, mas, também, consegue traçar um histórico e detalhar suas características atuais e até futuras, bem como as dos seus familiares, delimitando, assim, a sua herança genética. Assim, essa informação pode, porventura, ser de especial relevância não apenas ao indivíduo submetido ao teste - diretamente interessado, aliás -, mas, também para terceiros, como outras pessoas de sua família, empregadores, seguradoras, o próprio Estado, dentre outros (ECHTERHOFF, 2010).

Existem, entretanto, dois níveis de informação genética, para fins inclusive de alcance da proteção a ser conferida. A diferenciação aqui se mostra importante, na medida em que define o grau de proteção que essa informação deverá ter. Assim, ela pode ser primária, que diz respeito à espécie humana, sendo, portanto, de conhecimento coletivo (já que não é possível, por meio dela, a individualização do sujeito), ou secundária, que identifica a pessoa. Logo, é essa segunda categoria que carece de proteção especial pelo Direito (HAMMERSCHMIDT, 2008). 
Aliado aos avanços nos estudos do genoma humano, conclui-se que os testes ora em apreço não indicam só traços da personalidade, mas demonstram que existem características que são provenientes da carga genética, de forma que tais dados poderão servir de substrato para identificação e até julgamento de determinados indivíduos (ECHTERHOFF, 2010).

No ponto, Echterhoff (2010) traz pertinentes exemplos das consequências que o uso indevido dessas informações pode trazer. Na esfera familiar, que será melhor tratado mais adiante, pode acarretar na exposição de informações sobre a carga genética hereditária que não necessariamente são do interesse dos demais familiares, ocasionando alguma repercussão psicológica no descobrimento de uma predisposição ao desenvolvimento de uma doença incurável ou detentora de algum estigma social. Já no âmbito profissional, pode servir de justificativa para condutas discriminatórias, como a eliminação injusta de um processo seletivo ou disputa para um cargo, ou até mesmo, demissões.

Considerando o até aqui exposto, tem-se que o conceito de identidade genética revela quatro diferentes facetas. Primeiramente, cuida-se de direito universal, conferido à toda humanidade, devendo ser objeto de proteção pelo Direito. Em segundo lugar, a identidade genética intrínseca à existência humana, sendo involuntária (pois representa a carga genética herdada), indestrutível (já que não permanece no corpo humano mesmo após a morte), permanente (uma vez que não é alterada sem que haja uma ação externa que lhe dê ensejo), e singular (pois única, salvo nos casos de gêmeos univitelinos) (HAMMERSCHMIDT, 2008).

Portanto, resta evidente o caráter privado que as informações genéticas merecem, na medida em que, além de viabilizar a identificação dos dados acima narrados, constituem dado de natureza pessoal, já que possibilitam a individualização do indivíduo, estabelecendo seu histórico genético - e, como visto, inclusive o de seus familiares.

Delineadas linhas gerais no que diz respeito à informação genética, passa-se à análise da sua relação com a identidade dos sujeitos. Primeiramente, há de se diferenciar os conceitos de dados pessoais e dados de caráter pessoal, haja vista não se tratarem de sinônimos. Nesse sentido, Hammerschmidt (2008) alerta que os dados de caráter pessoal são espécies de dados pessoais, os quais, a seu turno, se referem a um sujeito identificável. Ademais, aplica-se aqui o "princípio da sensibilidade", o qual indica que os dados pessoais relativos à saúde são considerados informações sensíveis - chamados pela 
doutrina, portanto, de dados sensíveis"-, carecedores, assim, de uma proteção jurídica maior, já que ligados ao direito à intimidade.

De igual sorte são os dizeres de González (2011), que afirma serem os dados sensíveis profundamente ligados ao núcleo da personalidade e dignidade da pessoa humana, já que, ao permitirem a revelação de informações sobre várias pessoas (ou um sujeito individualizado, como mencionado acima), podem eventualmente servir de meio para a prática de condutas discriminatórias, merecendo, portanto, tutela jurídica maior. Nesse aspecto, somado ao direito à autodeterminação informativa (diante da relação que possui com o direito fundamental à privacidade), revela-se a necessidade dessa proteção especial, fundada num direito autônomo à proteção dos dados pessoais (SARLET; KEINERT, 2015).

No mesmo teor, a Declaração Internacional sobre Dados Genéticos Humanos da Unesco (DIDGH) consolidou a noção de que a informação genética são dados sensíveis, uma vez que por meio deles é possível verificar informações específicas do indivíduo, levando em consideração, inclusive, o meio ambiente como um dos elementos aptos à identificação do indivíduo. Em seu artigo $4^{\circ}$, faz constar que tais dados são sensíveis pois têm o condão de indicar predisposições genéticas dos sujeitos, as quais podem repercutir em todo o contexto familiar e social em que inserido (UNESCO, 2018).

A referida Declaração (assim como as demais que tratam da matéria, como a Declaração Universal sobre o Genoma Humano e os Direitos Humanos, a Declaração Universal de Bioética e Direitos Humanos e a Declaração das Nações Humanas sobre a Clonagem Humana, por exemplo) possui, em seu cerne, a preocupação de que a pesquisa genética não trate o indivíduo apenas como objeto a ser estudado, mas, sim, como pessoa que é. Assim, princípios como o da dignidade da pessoa humana e o autodeterminismo informativo (a ser melhor discorrido em tópico específico do presente artigo) possuem especial relevância aqui (RUARO, 2015).

Destarte, González (2011) prosseguindo com a diferenciação, ressalva que os dados genéticos que não revelem dados sobre a saúde - enquadrados, portanto, como dados pessoais - também possuem natureza íntima, na medida que são correlatos à dignidade e identidade do indivíduo.

Mostra-se, assim, a ligação intrínseca que os dados pessoais possuem com os direitos da personalidade. Estes podem ser definidos como aqueles intimamente ligados à condição humana, a ela inerentes, tanto considerada em si mesma quanto no meio social, 
"previsto no ordenamento jurídico exatamente para a defesa de valores inatos no homem, como a vida, a higidez física, a intimidade, a honra e a intelectualidade e outros tantos" (BITTAR, 2001). Ou, ainda, são considerados aqueles indispensáveis à pessoa, que os possui simplesmente em virtude da sua natureza humana (ECHTERHOFF, 2010).

No ponto, é deveras pertinente a conceituação dada por Oliveira (2004), para a qual os direitos da personalidade constituem numa soma de direitos e obrigações inerentes à pessoa, que surgem a partir do seu nascimento com vida. É, pois, o primeiro bem que comporá o seu patrimônio jurídico ao longo da sua existência.

Em que pese existir certa celeuma no que tange à diferenciação entre os direitos do homem e os da personalidade, há de se destacar que eles albergam os direitos à vida, integridade física, liberdade e de ação, se considerados os direitos da personalidade enquanto fundamentais. Doutra banda, se percebidos de forma horizontal, abrigam o direito à honra, nome, imagem, liberdade (de manifestação, pensamento e consciência), reserva sobre a intimidade, dentre outros (ECHTERHOFF, 2010).

Porém, considerando os direitos aqui tratados, os direitos da personalidade não podem se manter adstritos a discussões teóricas, devendo ser objeto de tutela independentemente da "categoria" em que enquadrados.

\section{INFORMAÇÕES NO ÂMBITO DA SAÚDE E NOVAS TECNOLOGIAS}

Diante de um mundo cada vez mais conectado pela internet, a utilização de tecnologias de informação e comunicação ("TICs") na área da saúde tem se tornado o meio mais eficaz para o desenvolvimento da universalização do acesso à saúde. Nesse contexto, surge a $e$-Health (ou "e-Saúde") ${ }^{4}$ como sistema que utiliza as tecnologias sem fio para desenvolver serviços de saúde, tanto pública quanto privada, de uma forma mais ampla e com maior alcance de acesso às informações (WORLD HEALTH ORGANIZATION, 2018).

Dentre os recursos comumente utilizados pelo modelo de e-Saúde, podem-se citar: a utilização de Prontuários Eletrônicos do Paciente ("PEP"), os variados serviços prestados por meio da Telemedicina, a utilização de sistemas de informação na esfera pessoal e administrativa, a $m$-Health - que se utiliza de dispositivos móveis para viabilizar

\footnotetext{
${ }^{4}$ Nomenclatura utilizada pela Organização Mundial de Saúde - OMS, adaptada ao contexto brasileiro sob o termo "e-Saúde".
}

Rev. de Biodireito e Direito dos Animais | e-ISSN: 2525-9695 | Porto Alegre | v. 4 | n. 2 | p. 1 - 21 | Jul/Dez. 2018 
os serviços respectivos -, e a customização dos serviços de saúde por meio da medicina personalizada (PORTAL TELEMEDICINA, 2018).

A prática da telemedicina ou telessaúde tem representado grande avanço na medicina brasileira, ao ponto que consegue promover um maior acesso a saúde, visto que possui um maior alcance de diferentes localidades, inclusive territórios isolados que contam apenas com um atendimento básico precário, reduzindo custos de consultas e diminuindo o tempo de espera para obtenção de diagnósticos ${ }^{5}$.

Não obstante, a utilização desta tecnologia pode gerar riscos à confidencialidade inerente a relação médico-paciente, na medida em que há uma exposição das informações passadas pelo paciente e uma insegurança quanto ao armazenamento destas uma vez que o atendimento é prestado através do uso de computadores e conexão via internet. Tais questões, assim, levam à discussões éticas e legais sobre a proteção da privacidade e dos dados transmitidos (REZENDE, 2013).

O prontuário médico, por sua vez, segundo integrante do Conselho Federal de Medicina, deve constar "de forma organizada e concisa, todos os dados relativos ao paciente, como seu histórico familiar, anamnese, descrição e evolução de sintomas e exames, além das indicações de tratamentos e prescrições" (CONSELHO FEDERAL DE MEDICINA, 1999). Desta forma, o uso do prontuário eletrônico, ao tornar possível o compartilhamento em rede dos dados do paciente de forma digital (já que facilita a compreensão das informações dantes escritas pelos profissionais), também se torna um fator de risco à privacidade do paciente e das instituições, pois ficam vulneráveis ao acesso indevido de terceiros (SARLET; KEINERT, 2015) - incluindo a atividade de possíveis hackers.

Seguindo esta mesma linha, tem-se o m-Health, nova ferramenta que instrumentaliza os serviços de saúde por meio de dispositivos móveis - tais como smartphones e tablets - igualmente promovendo uma qualidade no âmbito da saúde, ao possibilitar o acesso de forma eficiente a essas conveniências, na medida em que a utilização destes dispositivos tem se tornado cada vez mais comum na rotina da população. Esta eficiência recai também na quantidade de informações alcançadas, contribuindo para o repositório dos Registros Eletrônicos em Saúde (RES). Contudo, o tráfego facilitado de informações por estes dispositivos também podem gerar certa

\footnotetext{
${ }^{5}$ Por se entender que a terminologia telemedicina fica limitada ao setor médico, está se tornando comum a utilização do termo telessaúde por se entender mais abrangente.
}

Rev. de Biodireito e Direito dos Animais | e-ISSN: 2525-9695 | Porto Alegre | v. 4 | n. 2 | p. 1 - 21 | Jul/Dez. 2018 
insegurança do vazamento de informações, sobretudo na era das redes sociais (ANDRADE, 2014).

No que tange à medicina personalizada, ao utilizar testes genéticos, propõe um serviço exclusivo adaptado a cada organismo. Em que pese tais estudos genéticos apresentarem resultados mais assertivos de diagnósticos (além de possibilitar ações de medicina preventiva), o armazenamento e compartilhamento de dados genéticos, quando mal manipulados, podem desenvolver a categorização de riscos provenientes do perfil genético do indivíduo, culminando em uma "genetização da vida" e provocando a estigmatização de doenças. Estes fatores, consequentemente, tendem dar azo a condutas preconceituosas, tais como o reducionismo e determinismo genético, atingindo searas importantes da vida privada, como a familiar, a profissional, e até no que diz respeito à contratação de seguros e planos de saúde (RUARO; LIMBERGER, 2013).

Denota-se que a utilização deste conjunto de ferramentas tecnológicas na medicina, apesar de reduzir os custos operacionais, ampliando a assistência e o acesso dos pacientes à saúde, acaba por fazer uso de um grande volume de informações em saúde, classificadas por Sarlet e Keinert como "dados administrativos, assistenciais epidemiológicos e clínicos", os quais são angariados do indivíduo através da prestação direta dos serviços de saúde (SARLET; KEINERT, 2015). Por consequência, cria-se um ambiente no qual se torna mais possível a ofensa à privacidade, não só pelos dados manipulados, mas também porque com a utilização destas tecnologias se torna quase impossível não deixar rastros eletrônicos que se relacionam com a intimidade do indivíduo usuário (MOLINARO; RUARO, 2013).

Observa-se, portanto, que diante do amplo acesso à saúde, paralelamente, existe o risco de potencializar o interesse de terceiros não envolvidos na relação da prestação de serviço da saúde às informações pessoais do titular-paciente, como será melhor disposto no tópico seguinte.

As informações em saúde, sobretudo as análises genéticas médicas, por mais que se refiram à pessoa do seu titular, ultrapassam a esfera individual, podendo recair em interesses de terceiros, que, por sua vez, geram conflitos éticos. Segundo elencado por Joaquím Clotet (2009), tais conflitos podem se relacionar com o sujeito titular dos dados, nas ocasiões em que há a recusa do seu conhecimento; com os demais membros da família, os quais podem, sem que seja do seu conhecimento, portar as mesmas patologias do titular dos dados - e, assim, demandarem tomar conhecimento disto -; com o cônjuge 
do titular do dado, para que tenha ciência da carga genética hereditária dos seus (possíveis) descendentes; com pessoas (jurídicas ou naturais) com quem o titular tenha algum tipo de vínculo; com a própria sociedade, quando da investigação de algum crime; e, por fim, da própria pesquisa médica, que necessita, para seu fomento, do conhecimento de dados relativos à hereditariedade de algumas características genéticas e eventuais patologias.

No que tange os conflitos de interesse dentro do âmbito familiar, ressalte-se que, de modo geral, eles orbitam ao redor do embate entre dois deveres incumbidos aos médicos, quais sejam: o dever de confidencialidade e o dever de proteger a vida e saúde de outra pessoa. Faz-se necessária, portanto, a análise do estado de necessidade de cada caso concreto, ponderando do consentimento (ou não) do paciente, com a possibilidade (ou não) de perigo iminente à saúde (HAMMERSCHMIDT, 2008), Como exemplos de algumas situações de interesse familiar, pode-se citar a busca pela paternidade, a informação sobre a herança patológica, a proteção da identidade genética dos reproduzidos pelo método heterólogo, etc. Nesse contexto, as possíveis consequências suportadas pelo titular dos dados ocorrem no âmbito da relativização da sua privacidade em prol da proteção da saúde e da vida de seus descendentes.

Em relação ao âmbito das relações de trabalho, importante destacar que as informações em saúde e os dados genéticos do trabalhador se tornam relevantes ao passo que podem ser utilizadas de modo a reduzir os riscos no ambiente laboral. Por meio dos exames periódicos, é possível identificar as mutações induzidas pelo ambiente e, assim, tornar possível a identificação e eliminação (ou, ao menos, a redução) da causa do dano. De igual modo, com o uso da prova de controle genético torna-se identificável a sensibilidade do trabalhador a certos riscos ou toxinas expostas no espaço laboral. Desta forma, o acesso às informações em saúde do trabalhador pode ter vieses protetivo e preventivo da saúde, uma vez que os fatores de riscos serão conhecidos (HAMMERSCHMIDT, 2008).

Todavia, a utilização inadequada destes dados pode resultar em consequências gravosas ao titular das informações, como influenciar o empregador em sua decisão de contratação, desta forma caracterizando a "discriminação genética” conceituada como "o tratamento discriminatório é baseado no genótipo de indivíduos assintomáticos" (MYSSIOR; SILVA, 2016). 
A discriminação pautada no nível de exigência genética pode afetar também na contratação de seguros, uma vez que as empresas seguradoras podem se valer das informações de saúde do indivíduo para pautar as cláusulas contratuais dos seguros de vida, enfermidade e acidentes e, até mesmo, para negar a pactuação da contratação do serviço. Nesse cenário, há a ameaça da categorização de pessoas "não asseguráveis" baseadas em um reducionismo e determinismo genético capaz de relativizar a capacidade de autodeterminação (HAMMERSCHMIDT, 2008). Por essa razão, refuta-se a exigência de provas preditivas como condição para o contrato de trabalho ou de seguro, sendo tais provas permitidas apenas nos casos de "enfermidade genética existente; ser o indivíduo portador de um gene responsável por uma enfermidade; e em caso de predisposição ou suscetibilidade genética, a uma enfermidade” (MYSSIOR; SILVA, 2016).

Diante do aqui exposto, percebe-se que as questões de interesse de terceiro são dilemas que podem colocar em conflito a esfera coletiva (o efetivo acesso à saúde) e a esfera individual de proteção das informações e dados pessoais (envoltos pela intimidade). Assim sendo, é latente a necessidade de uma análise mais específica sobre as pesquisas genéticas e os desdobramentos da liberdade científica no âmbito dos direitos constitucionais fundamentais.

\section{LIBERDADE DE PESQUISA GENÉTICA E O CONFLITO ENTRE DIREITOS FUNDAMENTAIS}

Em linha com as questões até aqui expostas, torna-se claro que, apesar de o desenvolvimento científico e o uso das tecnologias na área da saúde promoverem a proteção de direitos fundamentais, também colabora para a potencialização dos riscos de violação a estes direitos. Assim, se destaca a relevância do equilíbrio dialético entre a liberdade de expressão, em seu viés científico, e o autodeterminismo informativo, em prol da proteção plena dos dados genéticos.

A liberdade de expressão refere-se a um pressuposto intrínseco da atividade científica, não sendo compatível o desenvolvimento de uma pesquisa científica sob a imposição de um controle rígido calcado em restrições temerárias (FRANCO, 2009). Dessa forma, a liberdade cientifica é reconhecida como "o direito à livre atividade intelectual” que deságua tanto nos interesses do pesquisador/cientista, quanto da 
coletividade ao promover benefícios resultantes do avanço biotecnológico (HAMMERSCHMIDT, 2008).

Notoriamente, não se pode refutar as vantagens decorrentes das pesquisas genéticas, posto que, ao tornar possível o conhecimento acerca da origem das patologias, promove alternativas de prevenção e cura das mazelas que acometem a sociedade (RUARO; LIMBERGER, 2013). E, individualmente, possibilita a medicina personalizada, como referido alhures, que, por meio do mapeamento genético, viabiliza tratamentos específicos para o paciente.

Nesse contexto, não obstante a necessidade do incentivo ao desenvolvimento da pesquisa científica com o objetivo da promoção da qualidade de vida dos indivíduos, a liberdade presente na atividade deve estar pautada no respeito aos direitos individuais dos sujeitos pesquisados. Assim, no ápice da utilização das tecnologias na sociedade da informação, se tem o direito fundamental à autodeterminação informativa, que protege o individuo no âmbito do acesso, tratamento e manipulação das suas informações pessoais (tanto as gerais, quanto as de saúde e as genéticas) (GONZÁLEZ, 2011).

A terminologia "autodeterminação informativa", criada pelo Tribunal Constitucional Federal Alemão em 1983, fora apresentada inicialmente na sentença da Lei do Censo (RUARO; LIMBERGER, 2013) e caracteriza-se como o poder do sujeito titular das informações em "além de controlar seu armazenamento, uso e veracidade, impedir totalmente a sua utilização" (ECHTERHOFF, 2010). Tal direito ganha destaque diante do elevado risco gerado pela má utilização dos dados sensíveis, posto que, como supracitado, é alta a possibilidade de ocasionar danos, especialmente os de cunho discriminatório.

Nesse sentido, oportuno mencionar que a noção de que os dados pessoais devem gozar de proteção especial pelo Direito surgiu pelos norte-americanos Samuel Warren e Louis D. Brandeis, com o artigo "The right to privacy", o qual tratava do direito à proteção da pessoa e o de estar sozinho. Ressaltou-se, ali, a ideia de que o indivíduo é titular das informações a ele relacionadas, incumbindo a ele a decisão sobre torna-las públicas ou não (RUARO; RODRIGUEZ; FINGER, 2011).

É a partir desse entendimento que se destaca, no âmbito da atividade científica, a imposição do "consentimento informado" como forma de assegurar a autodeterminação informativa do participante da pesquisa (RUARO; LIMBERGER, 2013). Esta proteção se estende à noção dinâmica da esfera privada, na qual o sujeito, pautado no princípio da 
autonomia, constrói sua própria identidade quando seleciona as informações que constituem a sua intimidade genética. Soma-se a isso, inclusive, a manifestação da vontade de não ser informado sobre certos dados (CLOTET, 2009).

A pesquisa genética, ao obedecer aos princípios da beneficência (melhoramento da saúde) e não-maleficência (não causar dano), contribui para um maior acesso à saúde, uma vez que transmite informações sobre a realidade do genoma - tanto em caráter individual, quanto coletivo - viabilizando a tomada de ações mais eficazes para o enfrentamento das questões médicas. Desta forma, acaba por gerar deveres tanto para o Estado, pois cabe a ele a garantia das condições que propicia o avanço das pesquisas científicas genéticas, quanto para os cientistas, posto que cabe a eles a promoção da reflexão, tanto ética quanto social, atinente aos benefícios e malefícios ao redor da manipulação e terapia genética (CLOTET, 2009).

Posto isso, observa-se que, não obstante o emprego das novas tecnologias oportunize uma democratização da pesquisa científica, faz-se necessário o exercício do dever estatal de proteção aos dados pessoais. Ademais, diante do caráter sensível conferido a esses dados pessoais em saúde, impõe-se uma maior proteção jurídica tendo em vista que potencializam embates entre direitos fundamentais (RUARO; LIMBERGER, 2013).

A liberdade de expressão e a criação científica, ao serem reconhecidas constitucionalmente pelo texto do art. $5^{\circ}, \mathrm{IX}^{6}$, concebem o caráter fundamental ao direito de liberdade de pesquisa científica. Não obstante, a manipulação de determinadas informações em saúde - sobretudo quanto ao genoma - impacta diretamente na dignidade dos indivíduos componentes da pesquisa. Assim, elevada é a preocupação que os seus titulares deixem de ser vistos como sujeitos de direito que são, para serem observados como meros objetos a serem manipulados (RUARO, 2015).

A dignidade humana, como fonte primária, relaciona-se tanto com a pesquisa genética quanto com a proteção de dados pessoais que a compõe. Sendo assim, oportuno salientar que, ainda que a atividade científica seja legítima, ela não é absoluta, devendo

\footnotetext{
${ }^{6}$ Art. $5^{\circ}$ Todos são iguais perante a lei, sem distinção de qualquer natureza, garantindo-se aos brasileiros e aos estrangeiros residentes no País a inviolabilidade do direito à vida, à liberdade, à igualdade, à segurança e à propriedade, nos termos seguintes:

$[\ldots]$

IX - é livre a expressão da atividade intelectual, artística, científica e de comunicação, independentemente de censura ou licença;
}

Rev. de Biodireito e Direito dos Animais | e-ISSN: 2525-9695 | Porto Alegre | v. 4 | n. 2 | p. 1 - 21 | Jul/Dez. 2018 
ser limitada em função da possibilidade de violação aos direitos fundamentais individuais, como a privacidade, proteção de dados pessoais, livre desenvolvimento da personalidade, princípio da igualdade de oportunidades, dignidade e integridade das pessoas (RUARO; LIMBERGER, 2013).

A utilização de tecnologias no armazenamento de informações genéticas em banco de dados virtuais facilita a vulnerabilização do indivíduo, uma vez que torna mais viável o cruzamento e vazamento de dados sensíveis. Nesse sentido, Echterhoff afirma que "é indispensável se buscar um meio termo entre o 'endeusamento' do conhecimento genético e a sua 'demonização', pois a técnica, o conhecimento em si pode ser considerado neutro, mas sua utilização pode ser redirecionada para interesses escusos" (ECHTERHOFF, 2010).

Seguindo esta linha de raciocínio, Ruaro (2015) acentua a aplicação dos princípios da prevenção e precaução como garantidores da coexistência dos direitos fundamentais em colisão - liberdade de pesquisa e intimidade e proteção de dados pessoais. Posto que, ao analisar a transferência de dados pessoais dentro do mundo digital, resta demonstrada a existência do dano (ou, ao menos, as chances de ele ocorrer) e, assim, pode-se atuar com vistas a reduzi-lo ou evita-lo. À vista disso, se torna viável a possibilidade da imposição de limites à liberdade de pesquisa, resguardando, todavia, o seu conteúdo essencial.

A atividade da pesquisa genética, portanto, deve ser fundamentada não apenas pelos princípios bioéticos inerentes às relações na área da saúde (médicopesquisador/paciente-pesquisado), mas também pela antecipada cautela no tratamento dos dados pessoais. Assim sendo, não se impossibilita o progresso científico quando observado o risco, mas tão somente utiliza os avanços tecnológicos com uma maior coerência à finalidade da pesquisa, tendo em vista que a má utilização das informações gera danos individuais (intimidade/privacidade) e coletivos (acesso à informação e à saúde).

Fato é que, na atual sociedade da informação, "o corpo humano deixa de ter uma arquitetura predominantemente orgânica e mecânica para constituir-se como um 'sistema de informação' ou, 'sistema de dados pessoais genéticos'” (RUARO, 2015). Desse modo, as informações relacionadas à saúde, por refletirem a necessidade de sigilo (que, se violada, pode gerar consequências discriminatórias), bem como o direito à autodeterminação informativa, por relacionarem-se com o direito fundamental à 
privacidade, requerem uma proteção especial, calcada no direito autônomo de proteção de dados pessoais (SARLET; KEINERT, 2015).

Isto posto, denota-se que, por meio da adoção dos princípios supracitados principalmente o da dignidade da pessoa humana -, torna possível a relação dialética entre as vantagens e prejuízos obtidos, de forma a compatibilizar a existência e proteção do direito à privacidade e intimidade e da liberdade de pesquisa genética.

\section{PROTEÇÃO NORMATIVA DOS DADOS GENÉTICOS}

No Brasil, até há pouco não existia uma proteção específica aos dados pessoais, tampouco no que tange a utilização destes no âmbito da saúde. A proteção da privacidade, como direito fundamental, está inclusa na Constituição Federal, dentre o rol dos direitos fundamentais previstos no já mencionado artigo $5^{\circ}$ da Constituição Federal (a saber, no inciso $\mathrm{X})^{7}$, bem como a intimidade e vida privada. Aliás, parte da doutrina relaciona a crescente preocupação com a proteção de dados como embrionária do instituto do habeas data (DONEDA; MENDES, 2013). Não obstante, a legislação infraconstitucional também já previa outros mecanismos de defesa a esses dados.

Nesse sentido, o Código Civil também garante a proteção à vida privada ${ }^{8}$ O Código de Defesa do Consumidor, regula os bancos de dados cadastrais nas relações consumeristas $^{9}$. O Código Penal, a seu turno, possui um capítulo próprio destinado aos

\footnotetext{
${ }^{7}$ Art. $5^{\circ}$ Todos são iguais perante a lei, sem distinção de qualquer natureza, garantindo-se aos brasileiros e aos estrangeiros residentes no País a inviolabilidade do direito à vida, à liberdade, à igualdade, à segurança e à propriedade, nos termos seguintes:

$[\ldots]$

$\mathrm{X}$ - são invioláveis a intimidade, a vida privada, a honra e a imagem das pessoas, assegurado o direito a indenização pelo dano material ou moral decorrente de sua violação;

${ }^{8}$ Art. 21. A vida privada da pessoa natural é inviolável, e o juiz, a requerimento do interessado, adotará as providências necessárias para impedir ou fazer cessar ato contrário a esta norma.

${ }^{9}$ Art. 43. O consumidor, sem prejuízo do disposto no art. 86, terá acesso às informações existentes em cadastros, fichas, registros e dados pessoais e de consumo arquivados sobre ele, bem como sobre as suas respectivas fontes.

$\S 1^{\circ}$ Os cadastros e dados de consumidores devem ser objetivos, claros, verdadeiros e em linguagem de fácil compreensão, não podendo conter informações negativas referentes a período superior a cinco anos. $\S 2^{\circ} \mathrm{A}$ abertura de cadastro, ficha, registro e dados pessoais e de consumo deverá ser comunicada por escrito ao consumidor, quando não solicitada por ele.

$\S 3^{\circ} \mathrm{O}$ consumidor, sempre que encontrar inexatidão nos seus dados e cadastros, poderá exigir sua imediata correção, devendo o arquivista, no prazo de cinco dias úteis, comunicar a alteração aos eventuais destinatários das informações incorretas.

$\S 4^{\circ}$ Os bancos de dados e cadastros relativos a consumidores, os serviços de proteção ao crédito e congêneres são considerados entidades de caráter público.
}

Rev. de Biodireito e Direito dos Animais | e-ISSN: 2525-9695 | Porto Alegre | v. 4 | n. 2 | p. 1 - 21 | Jul/Dez. 2018 
crimes que dizem respeito à violação do sigilo $^{10}$. Portanto, mesmo quando não vista a proteção dos dados pessoais como direito autônomo, ela é interpretada como consequência do direito à intimidade (LIMBERGER, 2017).

Porém, no que tange à proteção de dados pessoais propriamente dita, em 29 de maio de 2018, a Câmara dos Deputados aprovou o Projeto de Lei $\mathrm{n}^{\circ}$ 4.060/2012 - PLC 53/2018 (BRASIL, 2018a) -, o qual foi sancionado em 14 de agosto de 2018, dando origem à Lei $\mathrm{n}^{\mathrm{o}}$ 13.709/18 (BRASIL, 2018b), que estabelece regras sobre o tratamento dos dados pessoais pelo Poder Público e iniciativa privada, espelhando, em alguns pontos, as regras estabelecidas pelo Regulamento Geral sobre Proteção de Dados Pessoais (GDPR) (BRASIL, 2012).

A lei sancionada, com vacatio legis de dezoito meses, busca proteger a privacidade, abrangendo quaisquer empresas ou órgãos governamentais que porventura tenham processados dados no país, ou de pessoas que estejam no Brasil. Ela também estabelece regras para o processamento de dados atinentes à saúde, dentre eles, a vedação do seu uso para fins econômicos, salvo autorização expressa do indivíduo. Pelo texto, órgãos de pesquisa poderão acessar os bancos de dados pessoais para a realização de estudos relativos à saúde pública, mas num ambiente controlado e seguro, tratando de forma anônima as informações obtidas sempre quando for possível, com vistas a dificultar a identificação do proprietário do dado.

Particularmente no que tange aos dados relativos à saúde, a Lei n ${ }^{\circ} 13.709 / 18$ os enquadra como dados sensíveis, ao lado dos dados concernentes aos dados genéticos ou biométricos, à origem racial ou étnica e as informações sobre a religião ou filiação partidária. Quanto ao seu tratamento, há a delimitação de que somente será realizado, dentre outras hipóteses, "para a tutela da saúde, com procedimento realizado por profissionais da área da saúde ou por entidades sanitárias". Ainda, há a vedação da comunicação ou compartilhamento entre os responsáveis dos dados sensíveis relativos à

\footnotetext{
$\S 5^{\circ}$ Consumada a prescrição relativa à cobrança de débitos do consumidor, não serão fornecidas, pelos respectivos Sistemas de Proteção ao Crédito, quaisquer informações que possam impedir ou dificultar novo acesso ao crédito junto aos fornecedores.

$\S 6^{\circ}$ Todas as informações de que trata o caput deste artigo devem ser disponibilizadas em formatos acessíveis, inclusive para a pessoa com deficiência, mediante solicitação do consumidor.

${ }^{10}$ Art. 153 - Divulgar alguém, sem justa causa, conteúdo de documento particular ou de correspondência confidencial, de que é destinatário ou detentor, e cuja divulgação possa produzir dano a outrem: [...]

Art. 154 - Revelar alguém, sem justa causa, segredo, de que tem ciência em razão de função, ministério, ofício ou profissão, e cuja revelação possa produzir dano a outrem:
} 
saúde, com vistas à obtenção de vantagem econômica, excetuada a hipótese de portabilidade dos dados, com a autorização do seu titular.

A novel legislação determina que os dados somente serão processados após o consentimento do seu titular, o qual será posterior à ciência das consequências da não autorização, e poderá ser revogado a qualquer tempo. Será necessária outra autorização no caso de compartilhamento de tais dados com terceiros. Ademais, as partes submetidas à futura lei necessitarão prover meios de as pessoas obterem acesso aos dados, procedendo a retificações se for o caso, e até exclui-los. Deverá, ainda, existir a possibilidade da portabilidade dessas informações.

Eventual vazamento dos dados acarretará em aplicação de sanções aos responsáveis pelo tratamento - que deverão informar o titular imediatamente -, mesmo no caso de ter ocorrido via empresa parceira, concernentes à aplicação de advertências, multa (que pode chegar a $2 \%$ do seu faturamento, até o limite de $\mathrm{R} \$ 50$ milhões), além de outras obrigações de ordem procedimental (como, por exemplo, a eliminação dos dados vazados).

Tais regras, entretanto, não se aplicam quando os dados forem tratados por pessoa natural com objetivos pessoais, jornalísticos, acadêmicos ou artísticos, e, para o Estado, se para fins de segurança pública, defesa nacional ou na investigação de delitos.

Isto posto, observa-se que ainda que o cenário jurídico brasileiro, motivado pela movimentação vista na Europa com o GDPR, finalmente caminha para um nível de proteção à privacidade mais elevado, precipuamente apoiada na dignidade da pessoa humana, com vistas a salvaguardar o "direito fundamental à proteção de dados pessoais" (SARLET; MARINONI; MITIDIERO, 2018).

O GDPR foi editado em 24 de maio de 2016, quando foi estabelecido um prazo de dois anos para que empresas, governo e sociedade se adequassem às normas nele estabelecidas (prazo este que se findou em 25 de maio de 2018). Trata-se de importante marco regulatório sobre a temática da proteção de dados que, inclusive, fomentou a tramitação de projetos de lei, como no Brasil, que versam sobre o tema.

O regulamento define como dado pessoal toda e qualquer informação relativa a uma pessoa identificada ou identificável, direta ou indiretamente, especialmente no que diga respeito a localização geográfica, identificação online, bem como dados físicos, psicológicos, genéticos, econômicos, culturais ou sociais do indivíduo (CONSELHO DA UNIÃO EUROPEIA, 2015).

Rev. de Biodireito e Direito dos Animais | e-ISSN: 2525-9695 | Porto Alegre | v. 4 | n. 2 | p. 1 - 21 | Jul/Dez. 2018 
No que tange aos dados atinentes à saúde, o Regulamento também os trata como dados sensíveis, determinando que assim o serão considerados aqueles que revelem sobre o estado de saúde (física e mental) pretérito, atual ou futuro do seu titular, incluindo a prestação de serviços de saúde. As informações são expostas de forma ampla, ou seja, qualquer dado que indique doença (ou risco de), deficiência, histórico e tratamento clínico, independentemente da forma como recolhido. Também há menção aos dados genéticos, assim definidos como aqueles pessoais que dizem respeito à carga genética herdada ou adquirida, que forneçam informações sobre a fisiologia ou a saúde, oriundos de análise de amostra biológica do seu titular.

Nesse sentido, há a determinação expressa que as categorias especiais de dados pessoais que merecem proteção mais elevada só deverão ser objeto de tratamento para fins relacionados com a saúde nas ocasiões em que necessário para alcançar o interesse dos indivíduos ou da sociedade como um todo, dentro de um contexto que o justifique.

Logo, há a vedação de que o tratamento desses dados, elencados dentro de categoria especial, revelem, dentre outras informações, dados relativos à saúde do indivíduo. Contudo, o Regulamento excepciona essa vedação ao referir que, quando o tratamento for necessário para fins de medicina preventiva ou do trabalho, o diagnóstico médico, a prestação de cuidados ou tratamentos de saúde ou a gestão de sistemas e serviços de saúde, quando orientado por um contrato com um profissional da área. Também, se por motivos de interesse público na seara da saúde pública, dentre elas ameaças transfronteiriças graves para a saúde ou assegurar um elevado nível de qualidade e segurança dos cuidados de saúde, medicamentos ou dispositivos médicos.

Ademais, como determinado no artigo $6^{\circ}$ do Regulamento, somente será considerado legal o processamento de dados se houver: consentimento do titular, necessidade para execução de um contrato do qual o titular seja parte, necessidade para cumprir obrigação legal ou proteção de interesse vital do titular ou terceiros, for imprescindível para cumprimento de ato de interesse público ou servir de requisito à consecução de interesses dos legitimados.

Destarte, é notória a preocupação com os dados pessoais, principalmente os sensíveis, que o GDPR busca estabelecer, principalmente em virtude da crescente facilidade no acesso à informação, que deve vir acompanhada de meios que assegurem a privacidade e intimidade dos titulares dos dados. 


\section{CONCLUSÃO}

Já tecidas algumas reflexões sobre a correlação entre a liberdade de expressão e a proteção dos dados genéticos e da saúde, é possível obter algumas conclusões.

Inicialmente, foram feitos comentários atinentes à informação genética, assim considerada como aquela que diz respeito à herança genética do indivíduo para, então, tratar dos dados sensíveis, assim considerados aqueles que dizem respeito à saúde do seu titular. Diante da intrínseca relação dos dados dessa natureza com os direitos da personalidade, bem como a dignidade da pessoa humana, concluiu-se que eles são carecedores de uma tutela maior e mais abrangente do Direito.

Em seguida, discorreu-se das características e tendências da e-Health no ordenamento jurídico pátrio, assim como pode se constatar que ela impacta nos dados sensíveis. Em que pese as facilidades que a telemedicina traz ao dia-a-dia, verificou-se que esse instrumento deve ser utilizado com cautela, diante do risco à privacidade que pode surgir do seu mau uso.

Então, passou-se à análise do possível confronto que pode ocorrer entre o direito da liberdade de expressão, orientado pelo autodeterminismo informativo, frente ao direito à privacidade e intimidade, bem como ao da proteção dos dados genéticos no campo da pesquisa. Foi possível atestar que, é possível ponderar do uso da telemedicina, desde que resguardados os direitos fundamentais à privacidade e à intimidade, assim como o direito da liberdade de pesquisa genética.

Após, foi tratado da proteção normativa aos dados genéticos, tanto no plano nacional, quanto no internacional, no que diz respeito ao GDPR. No Brasil, não existe uma legislação que trate especificamente da proteção de dados, apesar de algumas leis infraconstitucionais mencionarem da proteção das informações. Nesse ponto, a própria Constituição Federal elenca como fundamental o direito à intimidade e privacidade. Existem, porém, projetos de lei em trâmite para versar justamente sobre o tema, em muito espelhados pelo GDPR, que regula da matéria na União Europeia. Servindo como norte, o GDPR entrou em vigor em 25 de maio de 2018, com normas específicas no que tange ao tratamento e coleta de dados pessoais, pautado, e muito, pelo consentimento dos seus titulares.

Concluiu-se, pois, que há uma grande fragilidade do tratamento das informações em saúde, precipuamente os dados genéticos, na realidade digital atual, mas tal 
dificuldade não deve representar óbice à pesquisa e ao avanço da ciência, levando-se em conta a relevância do estudo da liberdade de pesquisa genética. Há que se dar fomento ao avanço científico, porém, atentando-se à proteção aos direitos fundamentais dos titulares desses dados, que não devem ser usados para fins diversos a que se destinam e dando ênfase, sempre que possível, à privacidade dos sujeitos.

\section{REFERÊNCIAS}

ANDRADE, Michele Alberton et al. TI Móvel na Saúde: privacidade, confidencialidade e segurança. Bras Eng Bioméd, v. 1, n. 1, p. 2314-2317, 2014. Disponível em: <http://www.canal6.com.br/cbeb/2014/artigos/cbeb2014_submission_676.pdf> Acesso em 22 de mar. 2018.

BITTAR, Carlos Alberto. Os direitos da personalidade. 5. ed. rev., atual. aum. por Eduardo C. B. Bittar. Rio de Janeiro: Forense Universitária, 2001. p. 1.

BRASIL. Constituição da República Federativa do Brasil de 1988. Diário Oficial da União, Brasília, DF, 5 out. 1988. Disponível em: <http://www.planalto.gov.br/ccivil_03/constituicao/ConstituicaoCompilado.htm>. Acesso em 01 jun. 2018.

Decreto-Lei nº 2.848/40. Código Penal. Diário Oficial da União, Rio de Janeiro, RJ, 7 dez. 1940. Disponível em: <http://www.planalto.gov.br/ccivil_03/decretolei/Del2848compilado.htm>. Acesso em 01 jun. 2018.

. Lei $\mathrm{n}^{\circ} 10.406$, de 10 de janeiro de 2002. Institui o Código Civil. Diário Oficial da União, Brasília, DF, 10 jan. 2002. Disponível em: <http://www.planalto.gov.br/ccivil_03/leis/2002/L10406compilada.htm>. Acesso em 01 jun. 2018.

Lei $n^{\circ} 13.709$, de 14 de agosto de 2018. Dispõe sobre a proteção de dados pessoais e altera a Lei ${ }^{\circ} 12.965$, de 23 de abril de 2014 (Marco Civil da Internet). Diário Oficial da União, Brasília, DF, 14 ago. 2018. Disponível em: < http://www.planalto.gov.br/ccivil_03/_ato2015-2018/2018/Lei/L13709.htm>. Acesso em 19 ago. 2018.

Lei $\mathrm{n}^{\circ} 8.078$, de 11 de setembro de 1990. Dispõe sobre a proteção do consumidor e dá outras providências. Diário Oficial da União, Brasília, DF, 11 set. 1990. Disponível em: 〈http://www.planalto.gov.br/ccivil_03/Leis/L8078compilado.htm〉. Acesso em 01 jun. 2018.

Senado Federal. Projeto de Lei da Câmara PLC 53/2018. Dispõe sobre a proteção de dados pessoais e altera a Lei no 12.965, de 23 de abril de 2014. Disponível em: <https://www25.senado.leg.br/web/atividade/materias/-/materia/133486>. Acesso em 13 jun. 2018.

Rev. de Biodireito e Direito dos Animais | e-ISSN: 2525-9695 | Porto Alegre | v. 4 | n. 2 | p. 1 - 21 | Jul/Dez. 2018 
CLOTET, Joaquím. Bioética como ética aplicada e genética. Revista Bioética, v. 5, n. 2 , 2009.

CONSELHO DA UNIÃO EUROPEIA, 15 de dezembro de 2015, Proposal for a Regulation of the European Parliament and of the Council on the protection of individuals with regard to the processing of personal data and on the free movement of such data (General Data Protection Regulation). Disponível em: <https://eurlex.europa.eu/legal-

content/EN/TXT/?uri=uriserv:OJ.L_.2016.119.01.0001.01.ENG\&toc=OJ:L:2016:119:T OC>. Acesso em: 5 jun. 2018.

CONSELHO FEDERAL DE MEDICINA. Prontuário Médico. Disponível em: $<$ http://portal.cfm.org.br/index.php?option=com_content\&id=20462:prontuariomedico> Acesso em 22 de mar. 2018

DONEDA, Danilo; MENDES, Laura Schertel. Data protection in Brazil: new developments and current challenges. In: GUTWIRTH, Serge; LEENES, Ronald; HERT, Paul De (Org.). Reloading data protection: multidisciplinar insights and contemporary challenges. New York: Springer, 2013.

ECHTERHOFF, Gisele. Direito à privacidade dos dados genéticos. Curitiba: Juruá: 2010.

FRANCO, Alberto Silva. Genética humana e Direito. Revista Bioética, v. 4, n. 1, 2009.

GONZÁLEZ, Susana Álvarez. Derechos fundamentales y protección de datos genéticos. DYKINSON: Madrid, 2011.

HAMMERSCHMIDT, Denise. Intimidade genética \& direitos da personalidade. Curitina: Juruá, 2008.

LIMBERGER, Têmis. Mutações da privacidade e a proteção dos dados pessoais. In: RUARO, Regina Linden; MAÑAS, José Luis Piñar; MOLINARO, Carlos Alberto (Org.). Privacidade e proteção de dados pessoas na sociedade digital. Porto Alegre: Editora $\mathrm{Fi}, 2017$.

MOLINARO, Carlos Albeto; RUARO, Regina Liden. Internet y Estado de Vigilancia: El Desafío de la Protección de Datos. Disponível em: <http://hdl.handle.net/10923/11401> Acesso em 23 de mar. 2018.

MYSSIOR, Bárbara Augusta de Paula Araujo; SILVA, Luís Eduardo Gomes. Discriminação Genética: Uma Questão Jurídica Ou Biológica?. Revista de Biodireito e Direito dos Animais, v. 2, n. 2, p. 159-174, 2016.

OLIVEIRA, Flávia de Paiva Medeiros de. Genoma humano, direito à intimidade e novo código civil: problemas e soluções. Direito \& justiça: Revista da Faculdade de Direito da PUC-RS. Porto Alegre, v. 29, p. 111-124, 2004.

PORTAL TELEMEDICINA. O que é eHealth?. Disponível em: $<$ http://portaltelemedicina.com.br/o-que-e-ehealth/> Acesso em 22 de mar. 2018 
REZENDE, Edson Jose Carpintero, et al. Telessaúde: confidencialidade e consentimento informado. Rev Med Minas Gerais 2013; 23(3): 367-373, 2013. Disponível em: <http://www.rmmg.org/artigo/detalhes/223> Acesso em 22 de mar. 2018.

RUARO, Regina Linden. Direito fundamental à liberdade de pesquisa genética e à proteção de dados pessoais: os princípios da prevenção e da precaução como garantia do direito à vida privada. Revista do Direito Público, v. 10, n. 2, p. 15, 2015.

RUARO, Regina Linden; LIMBERGER, Têmis. Banco de dados de informações genéticas e administração pública como concretizadora da proteção dos dados pessoais e da dignidade humana. Revista NEJ - Eletrônica, Itajaí, v. 18, n. 1, p. 85-99, jan./abr. 2013. Disponível em: <http://dx.doi.org/10.14210/nej.v18n1.p85-99>. Acesso em 23 de mar. 2018.

$\begin{array}{ccccc}\text { dados } & \begin{array}{c}\text { RODRIGUEZ, Daniel Piñeiro; FINGER, Brunize } \\ \text { pessoais }\end{array} \text { e } \quad \text { O direito à proteção de } \\ \text { a } & \text { privacidade. } & \text { Disponível em: }\end{array}$
<https://revistas.ufpr.br/direito/article/view/30768/19876>. Acesso em 4 jun. 2018.

SARLET, Ingo Wolfgang. Direitos Fundamentais em Espécie. In: SARLET, Ingo Wolfgang; MARINONI, Luiz Guilherme; MITIDIERO, Daniel. Curso de Direito Constitucional. 5. ed. rev. e atual. São Paulo: Saraiva, 2018. p. 400-735.

KEINERT, Tania Margarete Mezzomo. $\mathrm{O}$ direito fundamental à privacidade $\mathrm{e}$ as informações em saúde: alguns desafios. In: KEINERT, Tania Margarete Mezzomo et al (Org.). Proteção à privacidade e acesso às informações em saúde: tecnologias, direitos e ética. São Paulo: Instituto de Saúde, 2015.

UNESCO. Declaração internacional sobre os dados genéticos humanos. Paris: Unesco, 2005.2 Disponível em: <http://unesdoc.unesco.org/images/0013/001361/136112porb.pdf>. Acesso em 3 jun. 2018.

WORLD HEALTH ORGANIZATION. eHealth. Disponível em: <http://www.who.int/ehealth/about/en/> Acesso em 22 de mar. 2018. 